\title{
A MATHEMATICAL MODEL FOR DISPERSAL OF BACTERIAL INOCULANTS COLONIZING THE WHEAT RHIZOSPHERE
}

\author{
ELIZABETH M. SCOTT, ${ }^{1}$ ELIZABETH A. S. RATTRAY. ${ }^{2}$ J. I. PROSSER, ${ }^{3 *}$ \\ K. KILLHAM ${ }^{2}$ L. A. GLOVER, ${ }^{3}$ J. M. LYNCH ${ }^{4} \uparrow$ and M. J. BAZIN' ${ }^{1}$ \\ 'Department of Microbiology, Division of Biosphere Sciences, Kings College, University of London, \\ Campden Hill Road, London W8 7AH, England, Departments of 'Plant and Soil Science and \\ ${ }^{3}$ Molecular and Cell Biology, University of Aberdeen, Marischal College, Aberdeen AB9 1AS, England \\ and ${ }^{4}$ Horticulture Research International, Worthing Road, Littlehampton, West Sussex BN17 6LP, \\ England
}

(Accepted 3 March 1995)

\begin{abstract}
Summary-A mathematical model has been constructed to describe bacterial growth and movement in the rhizosphere. In the model, bacteria are introduced into the soil on inoculated seeds and growth occurs, after seed germination, on material produced as root exudates. Movement of substrates away from the rhizosphere into the bulk soil is by diffusion and microbial movement is mediated by carriage on the root surface. The relationship between specific growth rate and substrate concentration is described by Monod kinetics and death occurs at a constant specific rate. An important component of the model is treatment of the effects of matric potential on the distribution and activity of bacteria in different microhabitats. Simulation of the model quantifies the distribution of both bacteria and substrate with depth and time in the rhizosphere and demonstrates significant differences between substrate concentrations at high and low matric potentials. Sensitivity analysis of model predictions indicates the parameters which govern microbial growth to be more important determinants of microbial movement than plant-associated parameters. Predictions of the model compared well with experimental data on microbial movement in the rhizosphere of wheat plants grown in microcosms, and inoculated with luminescence-marked Pseudomonas fluorescens, and provide the basis for quantitative risk assessment following environmental release of genetically-engineered microorganisms.
\end{abstract}

\section{INTRODUCTION}

Although microbial colonization of the rhizosphere has long been recognized, relatively little information is available concerning the dynamics of colonization. Such information is required not only for a better understanding of interactions between roots and indigenous soil microorganisms but also to facilitate the biotechnological development of microbial inocula for introduction into the rhizosphere. In addition, risk assessment of genetically-engineered microbial inocula released into the soil environment requires quantitative information on microbial survival and dispersal within the rhizosphere. The availability of molecular-based marker systems, such as the use of lux genes (Rattray et al., 1990), provides the enabling technology for characterization of rhizosphere colonization by an introduced microorganism, in the presence of other soil organisms.

Howie et al. (1987) have proposed that rhizosphere colonization by bacteria, from the germinating seed, proceeds in two phases. In the first phase, cells are

*Author for correspondence.

†Present address: School of Biological Sciences, University of Surrey, Guildford, Surrey GU2 5XH, England. carried passively with the root system as it extends. The second phase involves survival and growth and enables the population to fill the rhizosphere niche. The degree to which the niche is occupied by a bacterial species is a function of its colonization potential (Bennett and Lynch, 1981a,b), which considers the number of cells per unit length or weight of root.

The initial downward migration of bacteria from the seed may be mediated by a number of mechanisms. It may involve active motility of cells suspended in a water film on the root (Leben, 1983) or, more probably, in the grooves between epidermal cells (Parke et al., 1986). Movement may occur through convection of cells in water films, although there is no evidence for this. Dispersal of cells by roots may involve carriage by the extending root (Liddell and Parke, 1989), as well as by extending fungal hyphae associated with the root. In the presence of percolating water, dispersal of bacteria along the root system may occur by preferential flow since roots can create channels which cause water to bypass much of the matrix. The channels are partly created by diurnal expansion and contraction of roots (Faiz and Weatherley, 1982) and can enhance root colonization by the action of percolating water (Liddell and Parke, 
1989). Clearly the presence or absence of percolating water will largely determine the relative importance of mechanisms of cell movement, such as preferential flow along root channels and carriage along extending roots.

Without percolating water, there appears to be a strong control of rhizosphere colonization exerted by matric potential. Thresholds of matric potential have been identified below which microbial dispersal along root systems effectively ceases (Parke et al., 1986). Under drier conditions, water pathways will be too narrow for bacterial movement. Certainly, direct microscopic observation suggests that root colonization in unsaturated soils is largely restricted to water-filled grooves (Parke et al., 1986) and again points to the importance of matric potential as the dominant control on colonization.

The rhizosphere represents a key target environment for the biotechnological development of microbial inocula, as microbial symbionts such as rhizobia (Paau, 1989), as antagonists for control of soil-borne plant pathogens (Schippers, 1988) and for the production of plant-growth regulators (Kloepper et al., 1988). It is likely that the introduction of inocula will involve placement in seed coatings which are known to provide for effective rhizosphere colonization (Suslow and Schroth, 1982). Development of such rhizosphere inocula will be greatly facilitated by the ready availability of mathematical models which provide a predictive understanding of colonization dynamics.

Despite the importance of the rhizosphere, few attempts have been made to model microbial activity in this environment. Newman and Watson (1977) described microbial growth in relation to soluble $C$ substrate diffusing away from the root surface using a system of partial differential equations. This approach was further developed by Darrah (1991a) to take into account insoluble forms of rhizodeposition and the influence of a growing root (Darrah, 1991b). Such models represent valuable tools in the investigation of factors influencing microbial population dynamics in the rhizosphere but may have limitations since they consider the growing environment to be essentially homogeneous. In reality, a microbial population is not evenly distributed throughout the soil matrix, but exists as discrete subpopulations in soil pores sometimes isolated from other members of the total population. Each subpopulation will exist within its own growth environment influenced by distinct growth substrate, $\mathrm{O}_{2}$ and $\mathrm{H}_{2} \mathrm{O}$ conditions by virtue of its location within the soil architecture. Our aim was to develop a theoretical model which takes into account the influence of soil structure, and matric potential, on microbial growth as it dictates the distribution of microorganisms and water in the root-soil zone. This was accomplished by proposing hypotheses, based on assumptions, which were formulated in terms of a mathematical model. The model was made as simple as possible to be parsimonious with parameters, but sufficient to reflect the processes being investigated and to be experimentally testable. Predictions of the model were tested in soil-plant microcosms, operated at different matric potentials, and containing developing wheat root systems colonized by bioluminescence-marked $P_{\text {seu- }}$ domonas fluorescens, applied as a seed coating. Matric potentials were chosen to be realistic for an agricultural soil environment and to enable specific investigation of transport by root extension. with minimal movement by bulk water flow. Although these conditions were realistic, the primary aim of the experimental system was to obey the simplifying assumptions implicit in the theoretical model to enable critical testing of the underlying mechanistic assumptions on which the model was based.

\section{MATERIALS AND METHODS}

\section{Bacterial strains and growth}

P. Aluorescens 10586(FAC510) was a gift from S. Amin-Hanjani (University of Aberdeen) and contains chromosomally-inserted luxABE genes from Vibrio fischeri under the control of the tetracycline promoter from pBR322 (Amin-Hanjani et al., 1993). Cells of $P$. fluorescens were cultured routinely on L-broth medium ( $1 \%$ tryptone, $0.5 \%$ yeast extract, $0.5 \%$ $\mathrm{NaCl}, 0.1 \%$ glucose) and LB agar [L-broth containing $1.5 \%$ agar $(\mathrm{w} / \mathrm{v})]$ at $25^{\circ} \mathrm{C}$. The antibiotics used were kanamycin $(\mathrm{Km})\left(25 \mu \mathrm{g} \mathrm{ml}^{-1}\right)$ and rifampicin (Rif) (10 $\mu \mathrm{g} \mathrm{ml}^{-1}$ ).

\section{Preparation of microbial inocula}

Microbial inocula were prepared by growing $P$. fluorescens cells to late log-phase in L-broth containing $\mathrm{Km}$ and Rif. The cells were centrifuged $(1400 \mathrm{~g}, 30 \mathrm{~min})$ and washed twice in an equal volume of sterile, $1 / 4$ strength, Ringer's solution. Then the bacterial pellet was resuspended in an equal volume of Ringer's solution and a dilution series prepared in Ringer's solution for determination of viable cell concentration by plating on $\mathrm{LB}$ agar containing $\mathrm{Km}$ and incubating at $25^{\circ} \mathrm{C}$ for $48 \mathrm{~h}$. Wheat seeds were prepared by surface sterilizing in $2 \%(\mathrm{v} / \mathrm{v})$ sodium hypochlorite for $15 \mathrm{~min}$, washing in sterile water for $30 \mathrm{~min}$ and leaving for $16 \mathrm{~h}$ in a Petri dish containing moist, sterile filter paper. The sterile seeds were inoculated with luminescent $P$. fluorescens by coating with a mixture of cells and carboxy methylcellulose (2:1), to give a concentration of $10^{8}$ cells $\mathrm{g}^{-1}$ dry wt seed. Inoculation of surface-sterile seed ensured rapid colonization of the rhizosphere by the inoculum following germination.

\section{Effect of matric potential on rhizosphere colonization}

Microcosm experiments were performed to assess colonization of the wheat rhizosphere by luminescence-marked $P$. fluorescens in relation to matric potential. Microcosms consisted of two sheets of 
perspex $(25 \times 25 \times 0.3 \mathrm{~cm})$ held apart by $\mathrm{l} \mathrm{cm}$ strips of perspex, containing a sandy loam (Craibstone) soil [Countesswells series; pH (distilled water), 6.46; organic C, $2.47 \%$; organic $\mathrm{N}, 0.27 \%$; cation exchange

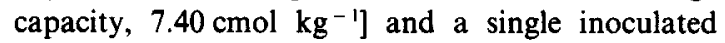
wheat seed. Soil was sieved to $<3 \mathrm{~mm}$ and packed to a bulk density of $1 \mathrm{~g} \mathrm{~cm}^{-3}$. Fresh, field wet soil was adjusted to $-100 \mathrm{kPa}$ and air-dried soil was adjusted to $-1500 \mathrm{kPa}$ according to moisture release characteristics to obtain water filled pores with largest neck diameters of 3 and $0.2 \mu \mathrm{m}$, respectively. Air-dried soil was required for the latter to bring the matric potential below $-1500 \mathrm{kPa}$, prior to rewetting. The inoculated seed was placed in the microcosm and grown in a plant growth cabinet under a light bank $\left(86,000 \mu \mathrm{mol} \mathrm{m}{ }^{-2} \mathrm{~s}^{-1}\right)$ with a $16 \mathrm{~h}$ photoperiod at a constant temperature of $15^{\circ} \mathrm{C}$. Every $7 \mathrm{~d}$, the wheat seedlings were carefully removed from the microcosms and the roots sectioned at $5 \mathrm{~cm}$ intervals from the seed. The root sections were shaken to remove loosely associated soil, placed in $1 / 4$ strength Ringer's solution and hand-shaken for $1 \mathrm{~min}$. Dilution plate counts were performed on LB agar containing $\mathrm{Km}$ and Rif (incubated for $48 \mathrm{~h}$ at $25^{\circ} \mathrm{C}$ ) for viable cell enumeration. A charge-coupled device (CCD; $385 \times 578$ pixels, each $22 \mathrm{~mm}$ square) camera (Model 1 nitrogen-cooled, Wright Instruments Ltd, Enfield, U.K.) and associated computer-imaging system (Dell system 310) were used to facilitate enumeration of luminescent colonies on solid media. For bright field visualization, the exposure time was $0.01 \mathrm{~s}$. Dark field exposure time was $2 \mathrm{~min}$, after application of $2 \mu 1$ (1:100 dilution) dodecanal to the lid of the Petri dish.

\section{Development of the mathematical model}

A simple layer model approach (Addiscott and Wagenet, 1985) was used to describe the growth of a root, and its subsequent colonization by a genetically. modified microorganism (GMM). The root-soil zone is depicted as a system of concentric cylinders divided horizontally into layers of equal depth. An inner cylinder defines the root, surrounded by a cylindrical rhizosphere and an outer cylinder of bulk soil (Figure 1). Organic substrate, in the form of sugar or another simple soluble organic compound, is exuded from the growing root and diffuses into the surrounding soil, providing a growth substrate for the microbial population in the rhizosphere. The physical structure of soil dictates the existence of a distribution of isolated niches or microhabitats with varying suitability for microbial colonization. To reflect this heterogeneity, the model assumes the growth of the GMM population to be dependent on distribution of the population among these microhabitats and the dispersal of water under a given moisture regime. The assumptions upon which the model is based are described below.

Root growth and microbial movement. The root is assumed to consist of a cylinder of radius $0.2 \mathrm{~mm}$, a value appropriate for a wheat root. The rhizosphere is assumed to extend $2 \mathrm{~mm}$ from the root surface, which is within the range indicated by experimental data of Rovira and Davey (1974), and the soil profile is delineated into layers of $5 \mathrm{~cm}$ in depth. The root extends downwards through the layers of soil, the relation between time after planting and depth of root being given by

$$
d_{\mathrm{r}}=A[1-\exp (-\beta r)]
$$

where $d_{\mathrm{r}}=$ depth from soil surface $(\mathrm{cm})$ and $t=$ time after planting (d). $A$ and $\beta$ are constants with values of $27.07 \mathrm{~cm}$ and $0.115 \mathrm{~d}^{-1}$, respectively. Such a description predicts the root to grow at the greatest rate over the first $10 \mathrm{~d}$ after planting and is consistent with the root growth observed in the experimental

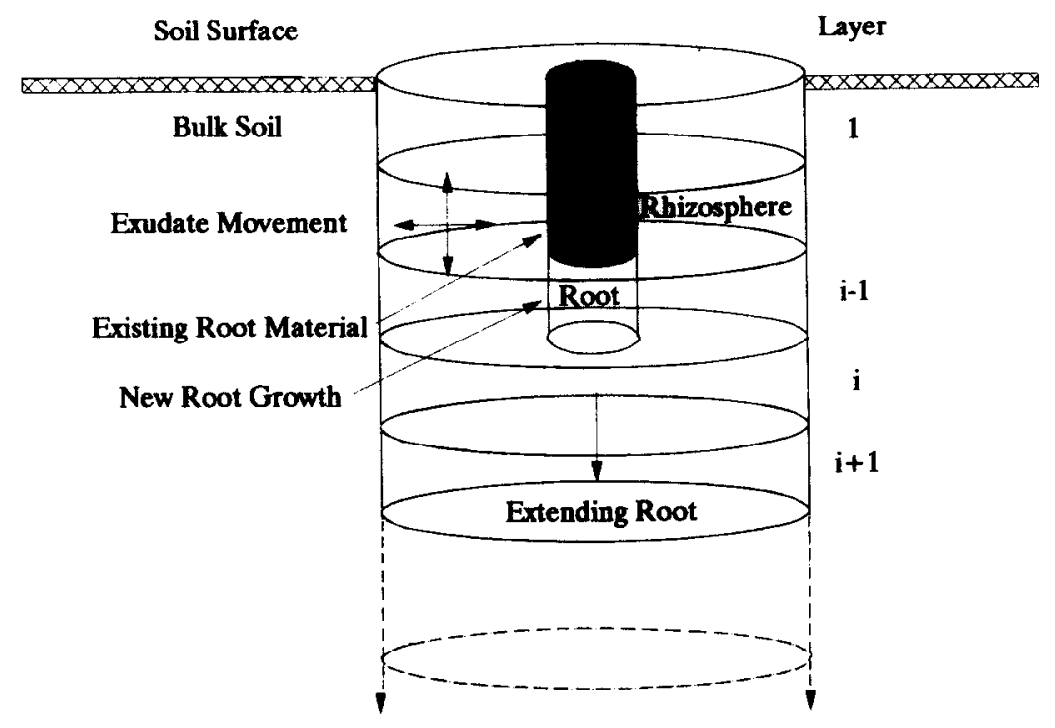

Fig. 1. Schematic representation of the root-rhizosphere region as described by the theoretical model. 
Table 1. Numerical values for the parameters and initial values used in simulation of the mathematical model

\begin{tabular}{|c|c|c|c|}
\hline Symbol & Meaning & Units & Value \\
\hline \multicolumn{4}{|c|}{ Soil characteristics } \\
\hline$D_{\mathrm{s}}$ & Diffusion coefficient of substrate in solution & $\mathrm{cm}^{2} \mathrm{~s}^{-1}$ & $0.5 \times 10^{-3}$ \\
\hline$f$ & Impedance factor & & $\begin{array}{l}0.01 \text { at }-1500 \mathrm{kPa} \\
0.17 \text { at }-100 \mathrm{kPa}\end{array}$ \\
\hline \multicolumn{4}{|c|}{ Root zone characteristics } \\
\hline \multirow[t]{2}{*}{$H f x_{\mathrm{sin}}$} & Rate of exudation of substrate & $\mu \mathrm{g} \mathrm{cm}^{-2} \mathrm{~d}^{-1}$ & $\begin{array}{l}0.25 \text { for } 0-7 \mathrm{~d} \\
0.05 \text { subsequently }\end{array}$ \\
\hline & Root radius & $\mathrm{mm}$ & 0.2 \\
\hline$d r$ & Width of rhizosphere and bulk soil & $\mathrm{mm}$ & 2 \\
\hline$d z$ & Depth of layer & $\mathrm{cm}$ & 5 \\
\hline \multicolumn{4}{|c|}{ Microbial characteristics } \\
\hline$\mu_{\mathrm{md}}$ & Maximum specific growth rate in dry habitat & h. & 0.5 \\
\hline$\mu_{\mathrm{mn}}$ & Maximum specific growth rate in wet habitat & $h-1$ & 0.1 \\
\hline$k_{i}$ & Death rate in dry habitat & h-i & 0.02 \\
\hline$k_{w}$ & Death rate in wet habitat & h 1 & 0.05 \\
\hline$K_{\mathrm{s}}$ & Saturation constant for growth & $\mu \mathrm{g} \mathrm{cm}$ & 4.0 \\
\hline$Y$ & Yield coefficient & $\mu \mathrm{g} \mu \mathrm{g}$ & 0.2 \\
\hline \multicolumn{4}{|c|}{ Initial conditions } \\
\hline & Seed coated inoculum & No. of cells & $4.0 \times 10^{6}$ \\
\hline$S_{0}$ & Initial substrate in rhizosphere and bulk soil & $\mu \mathrm{g} \mathrm{cm}{ }^{3}$ soil & 0 \\
\hline \multicolumn{4}{|c|}{ Variables } \\
\hline$G_{d}$ & GMM concentration in dry habitat & $\mu \mathrm{g} \mathrm{cm}^{-3}$ soil & \\
\hline$G_{w}$ & GMM concentration in wet habitat & $\mu \mathrm{g} \mathrm{cm}{ }^{-2}$ soil & \\
\hline$S_{\mathrm{r}}$ & Substrate concentration in rhizosphere soil & $\mu \mathrm{g} \mathrm{cm}-3$ soil & \\
\hline$S_{\mathrm{b}}$ & Substrate concentration in bulk soil & $\mu \mathrm{g} \mathrm{cm}^{-3}$ soil & \\
\hline
\end{tabular}

system. Since the experimental system is maintained at a constant matric potential, microbial movement by mass flow of water is assumed to be negligible. The only mechanism of microbial movement considered here is carriage on the growing root. As the root tip passes into a new layer, a fraction of the microbial population is translocated from the layer above. To simplify the mathematical description, the microbial population is assumed to be attached to the root surface and to be uniformly distributed throughout a particular layer, and the fraction transported to the layer below is taken to be the fraction of the soil layer that is occupied by the actively-extending root. In most species root cell division takes place in the apical $0.2 \mathrm{~cm}$, so that for a soil layer $5 \mathrm{~cm}$ in depth the translocated fraction will therefore be $0.2 / 5=0.04$.

Movement of root exudate. $\mathrm{C}$ substrate is exuded from the root at a rate which is dependent upon the age of the root in the layer. As the root moves into a new layer the age of that length of root is set to zero. The root then exudes substrate at a rate of $0.25 \mu \mathrm{g} \mathrm{cm}^{-2}$ $\mathrm{d}^{-1}$ for $7 \mathrm{~d}$, after which time the rate decreases to 0.05 $\mu \mathrm{g} \mathrm{cm}^{-2} \mathrm{~d}^{-1}$. Despite numerous investigations into the mechanisms and influencing factors of root $\mathrm{Closs}$, a full understanding, sufficient to obtain a time-dependent function describing root exudation, has yet to be realized. The parameters used here are based on the understanding that exudation is closely associated with root growth (Prikryl and Vancura, 1980), that the greatest quantities are lost from the root tip and zone of elongation (McDougall and Rovira, 1970) and that, for the experimental system, exudation is consistent with the range of $10-100 \mathrm{mg}$ exudate $\mathrm{g}^{-1}$ root dry wt increase suggested by Newman (1985). Movement of substrate from the root into the rhizosphere and the surrounding soil, and vertically between layers, occurs by diffusion. The horizontal fiux of substrate into the rhizosphere of the $i$ th layer of soil is denoted $H f x_{\mathrm{inr}}^{i}$ and is taken to be the exudation rate. From Fick's Law, the rate of substrate diffusion from the rhizosphere

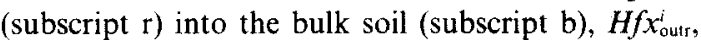
may be written as

$$
H f x_{\text {outr }}^{\prime}=-D_{\mathrm{s}} f \frac{s_{\mathrm{b}}^{\prime}-s_{\mathrm{r}}^{i}}{d r},
$$

where $D_{\mathrm{s}}\left(\mathrm{cm}^{2} \mathrm{~s}^{-1}\right)$ is the diffusion coefficient of the organic molecule in free solution, which for sugars, amino acids and simple organic compounds may be in the range $0.5-1.0 \times 10^{-5} \mathrm{~cm}^{2} \mathrm{~s}^{-1} ; f$ is an impedance factor which takes into account the tortuous pathway through the soil pores and will vary with soil water content [the values of $f$ shown in Table 1 were taken from the literature (D. Barraclough, unpubl. D.Phil thesis, Univ. of Oxford, 1976)]; $s_{\mathrm{b}}^{i}$ and $s_{\mathrm{r}}^{i}$ are the substrate concentrations $\left(\mu \mathrm{g} \mathrm{cm}^{-3} \mathrm{dry}\right.$ soil) in the bulk soil and rhizosphere of layer $i$, respectively; and $d r(\mathrm{~cm})$ is the distance from the root to the edge of rhizosphere. Since the experimental system discussed earlier contains only onc root, the cylinder of bulk soil as depicted in Figure 1 is assumed to be surrounded by a continuum of soil remaining at the initial substrate conditions, $s_{0}^{t}$. The concentration of nutrient in this distant region will be small compared to that in the rhizosphere and $s_{0}^{i}$ is taken to be zero. Horizontal movement of substrate from the $i$ th rhizosphere layer into the $i$ th bulk soil layer, $H f x_{\mathrm{inb}}^{i}$, is then given by Equation 2 and as an outer boundary condition the 
substrate loss from the $i$ th layer of bulk soil is represented by

$$
H f x_{\text {outb }}^{i}=-D_{\mathrm{s}} f \frac{s_{0}^{i}-s_{\mathrm{b}}^{i}}{d r},
$$

where $s_{0}^{i}$ is a constant. Similarly, movement of substrate between layers is by diffusion, so that the flux of substrate into the $i$ th layer from the $i^{-1}$ th layer, $V f x_{\mathrm{inn}}^{i}$, and out of the $i$ th layer into the $i+1$ th layer, $V f x_{\text {our }}^{i}$, are represented by

$$
V f x_{\mathrm{inr}}^{i}=-D_{\mathrm{s}} f \frac{\left(s_{\mathrm{r}}^{i-1}-s_{\mathrm{r}}^{i}\right)}{d z}
$$

and

$$
V f x_{\text {our }}^{i}=-D_{\mathrm{s}} f \frac{\left(s_{\mathrm{r}}^{i}-s_{\mathrm{r}}^{i+1}\right)}{d z},
$$

where $s_{\mathrm{r}}^{i-1}, s_{\mathrm{r}}^{i}$ and $s_{\mathrm{r}}^{i-1}$ are the substrate concentrations $\left(\mu \mathrm{g} \mathrm{cm}^{-3} \mathrm{dry}\right.$ soil) in the $i-1$ th, $i$ th and $i+1$ th layers, respectively, and $d z$ is the depth of each layer $(5 \mathrm{~cm})$. To describe the vertical movement of substrate between layers of bulk soil, these terms in Equation 4 and Equation 5 are replaced by, $s_{b}^{i-1}, s_{b}^{i}$ and $s_{b}^{i+1}$ and $V f x_{\text {inr }}^{i}$ and $V f x_{\text {outr }}^{i}$ by $V f x_{\text {inb }}^{i}$ and $V f x_{\text {outb }}^{i}$, respectively. For the upper boundary conditions $V f x_{\text {in }}^{i}$ and $V f x_{\text {inb }}^{i}$ are set to zero. The lower boundaries will be moving and are dictated by the movement of substrate as shown in Equation 4 and Equation 5, given an initial concentration in both the rhizosphere and bulk soil of $s_{0}$.

Influence of soil structure. The pore size distribution of a soil dictates the distribution of water within the soil at a given matric potential. If a soil pore is considered as an individual microhabitat for microbial colonization, then the size and distribution of these microhabitats will influence the distribution of introduced organisms (Filip and Kanazawa, 1985; Postma et al., 1989) and their subsequent survival (Postma et al., 1990). In this model only two assumptions are made regarding the influence of pore size distribution on microbial growth. Firstly, it is assumed that microorganisms in water-filled pores have a higher maximum specific growth rate than those in non-filled pores and secondly that the probability that a microorganism will be located in a pore of a certain size is related to the neck surface area of that pore.

At a given matric potential, the neck diameter of the largest water-filled pore is inversely proportional to the matric potential:

$$
d=\frac{300}{\Psi_{\mathrm{m}}},
$$

where $d$ is the pore neck diameter $(\mu \mathrm{m})$ and $\Psi_{\mathrm{m}}$ is the matric potential $(\mathrm{kPa})$ (Marshall, 1959). If it is assumed that a pore has a depth equal to its diameter, the soil moisture release curve can be used to estimate the number of pores of a particular neck diameter and to construct a frequency distribution of pore neck surface area. This frequency distribution is used to calculate the probability of a microorganism entering a water-filled or non-water-filled pore and accordingly the population is divided into two microhabitats-one with and one without the availability of water.

Microbial growth. The specific growth rate, $\mu\left(\mathrm{h}^{-1}\right)$, of the GMM at each position in the soil is determined by the concentration of substrate at that point and follows Monod growth kinetics (Monod, 1942). As described above, the GMM population is divided into two subpopulations according to their niche in the soil. It is assumed that organisms in a water-filled microhabitat will have a higher maximum specific growth rate than those in a non-water-filled microhabitat. The GMM populations in both microhabitats are assumed to die at a constant rate, $k$ $\left(h^{-1}\right)$.

Following the assumptions above, the rate of change of substrate concentration in the rhizosphere and subsequent microbial growth in the $i$ th layer of the rhizosphere is described by equations 7-9:

$$
\begin{aligned}
& \frac{\mathrm{d} G_{\mathrm{d}}}{\mathrm{d} t}=\mu_{\mathrm{md}}\left(\frac{S_{\mathrm{r}} G_{\mathrm{d}}}{S_{\mathrm{r}}+K_{\mathrm{s}} \theta}\right)-k_{\mathrm{d}} G_{\mathrm{d}}, \\
& \frac{\mathrm{d} G_{\mathrm{w}}}{\mathrm{d} t}=\mu_{\mathrm{mw}}\left(\frac{S_{\mathrm{r}} G_{\mathrm{w}}}{S_{\mathrm{r}}+K_{\mathrm{s}} \theta}\right)-k_{\mathrm{w}} G_{\mathrm{w}}
\end{aligned}
$$

and

$$
\begin{aligned}
\frac{\mathrm{d} S_{\mathrm{r}}}{\mathrm{d} t}= & \frac{A_{\mathrm{rh}}}{V_{\mathrm{r}}}\left(H f x_{\mathrm{inr}}-H f x_{\mathrm{outr}}\right) \\
& +\frac{A_{\mathrm{rv}}}{V_{\mathrm{r}}}\left(V f x_{\mathrm{inr}}-V f x_{\mathrm{our}}\right) \\
& -\frac{\mu_{\mathrm{md}}}{Y}\left(\frac{S_{\mathrm{r}} G_{\mathrm{d}}}{S_{\mathrm{r}}+K_{\mathrm{s}} \theta}\right) \\
& -\frac{\mu_{\mathrm{mw}}}{Y}\left(\frac{S_{\mathrm{r}} G_{\mathrm{w}}}{S_{\mathrm{r}}+K_{\mathrm{s}} \theta}\right) .
\end{aligned}
$$

For clarity the subscript $i$ has been omitted and $S_{\mathrm{r}}$ is the substrate concentration in the rhizosphere $\left(\mu \mathrm{g} \mathrm{cm}^{-3}\right.$ soil). $G_{\mathrm{d}}$ and $G_{\mathrm{w}}$ denote the GMM concentrations $\left(\mu \mathrm{g} \mathrm{cm}^{-3}\right)$ in the dry and wet microhabitats and are calculated from the soil moisture release characteristics as described previously. The maximum specific growth rates $\left(\mathrm{h}^{-1}\right)$ and specific death rates $\left(h^{-1}\right)$ in the dry and wet microhabitats are denoted by $\mu_{\mathrm{md}}$ and $\mu_{\mathrm{mw}}$ and $k_{\mathrm{d}}$ and $k_{\mathrm{w}}$, respectively. $K_{\mathrm{s}}$ is the saturation constant

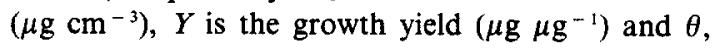
the soil water content $\left(\mathrm{cm}^{3} \mathrm{~cm}^{-3}\right)$, is included in Equations 7-9 since the saturation constant is measured per unit volume of soil solution and is calculated from the soil moisture release curve. $A_{\mathrm{rb}}$ and $A_{\mathrm{rv}}\left(\mathrm{cm}^{2}\right)$ are the horizontal and vertical areas of the rhizosphere over which the diffusion of substrate will take place and $V_{\mathrm{r}}$ is the volume of the rhizosphere $\left(\mathrm{cm}^{3}\right)$. To facilitate the comparison of experimental 
data with model predictions it was assumed that a bacterial cell has a mass of 1 pg dry wt.

As it is assumed that microbial migration is by carriage on the root surface alone, no microorganisms will exist in the bulk soil, so that the rate of change of substrate in the bulk soil of layer $i$ will be given by

$$
\begin{aligned}
\frac{\mathrm{d} S_{\mathrm{b}}}{\mathrm{d} t}=\frac{A_{\mathrm{bb}}}{V_{\mathrm{b}}}\left(H f x_{\mathrm{inh}}-\right. & \left.H f x_{\mathrm{outh}}\right) \\
& +\frac{A_{\mathrm{bv}}}{V_{\mathrm{b}}}\left(V f x_{\mathrm{inb}}-V f x_{\mathrm{outb}}\right) .
\end{aligned}
$$

Here, as in Equation 9, $A_{\mathrm{bh}}, A_{\mathrm{bv}}$ and $V_{\mathrm{b}}$ are the areas and volume of the bulk soil region.

Equations were solved using 4th-order RungeKutta numerical integration in FORTRAN 77 on an IBM-compatible PC. Table 1 shows the numerical values which were used to model root colonization by a GMM population under maintained moisture regimes of -1500 and $-100 \mathrm{kPa}$. All values were taken from available information on microbial growth in laboratory culture and all fall within the range of values used by Newman and Watson (1977) in their model of microbial growth in the rhizosphere

\section{Predictions of the mathematical model}

The model was simulated using values of constants and initial conditions given in Table 1, generating predictions of viable cell numbers as functions of both depth and time for $28 \mathrm{~d}$ after seed germination at two matric potentials, -100 and $-1500 \mathrm{kPa}$. The lower detection limit for predicted viable cell concentration was assumed to be 1 cell and numbers less than this, although predicted by the model, are not plotted.

At the higher matric potential, cells penetrated to greater depths, reaching $15-20 \mathrm{~cm}$ by day 7 , while dispersal to this depth at $-1500 \mathrm{kPa}$ was not predicted within $28 \mathrm{~d}$ (Figure 2). The total number of cells present in the soil at any particular time was greater at $-100 \mathrm{kPa}$, reflecting better supply of substrate to the cells at this matric potential. Growth of roots was the same at both matric potentials and nutrient production, by exudation, was consequently also the same. Differences in dispersal at the two matric potentials therefore result solely from greater vertical and horizontal diffusion of substrate to cells. The effects of this on predicted substrate concentration may be seen in Figure 3. At $-100 \mathrm{kPa}$, predicted substrate concentrations are low at all depths and are negligible by day 14 , due to rapid diffusion to cells, of all substrate exuded by roots. Death rates were assumed to be independent of matric potential and differences in total cell numbers, summed over all depth intervals, reflect differences in specific growth rate resulting from differences in substrate concentration and supply. The decline in cell numbers with depth was greater at $-1500 \mathrm{kPa}$ and was approximately exponential at $-100 \mathrm{kPa}$. Again this reflects differences in substrate diffusion at the two matric potentials.

For any particular depth interval, numbers initially declined as cells died, prior to significant root exudation and diffusion of nutrients to cells (Figure 4). The subsequent increase in cell numbers, where specific growth rate exceeded specific death rate, was followed by an approximately exponential decrease in numbers with time at $-100 \mathrm{kPa}$ and a more curvilinear decrease at $-1500 \mathrm{kPa}$. Thereafter, changes in cell numbers are determined mainly by specific death rates as little additional substrate will be available for growth. At $-1500 \mathrm{kPa}$, the same amount of substrate will be produced, but diffusion will be slower and substrate consequently accumulates to higher concentrations (Figure 3). Substrate concentrations are higher at all depths and although substrate limitation occurs at later time points, limitation is less than at $-100 \mathrm{kPa}$, giving later peaks in cell number and more prolonged growth. A further consequence of this is convergence of numbers at $0-5 \mathrm{~cm}$, which by day 28 were similar at both matric potentials. The model
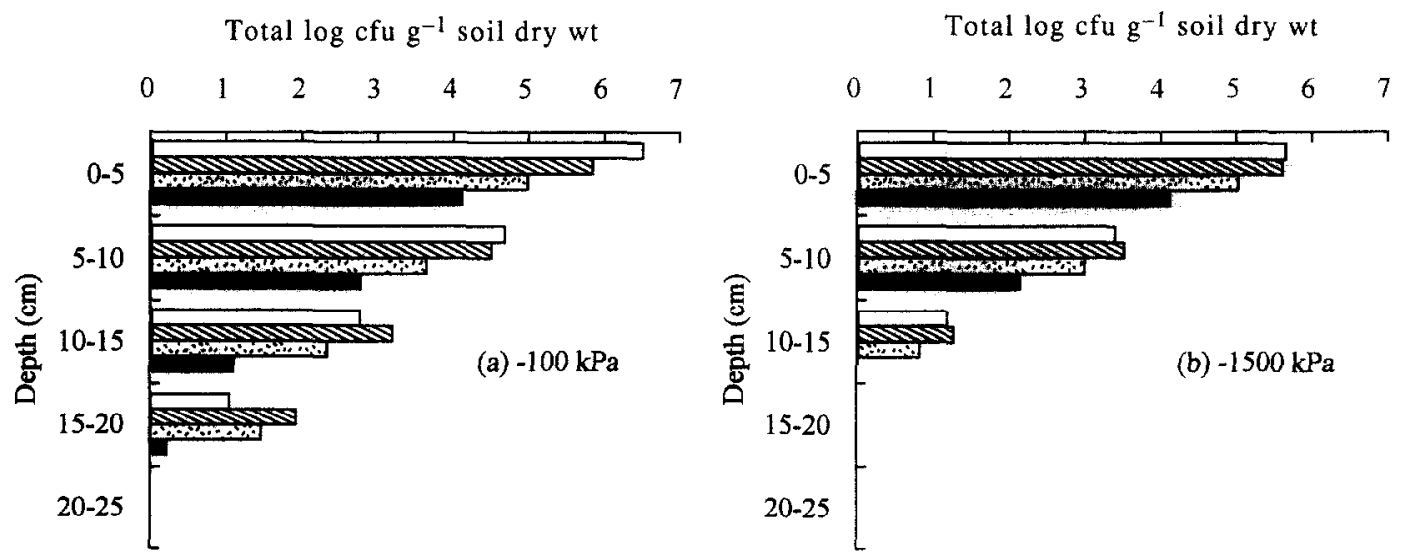

Fig. 2. Predicted changes in bacterial cell numbers with depth following germination of seed inoculated with

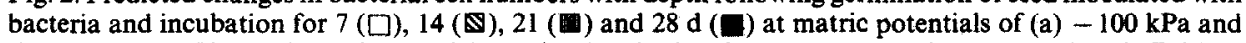
(b) $-1500 \mathrm{kPa}$. The mathematical model was simulated using the parameters and constants given in Table 1 . 
Concentration ( $\mu \mathrm{g} \mathrm{cm}{ }^{-3} \mathrm{dry}$ soil)

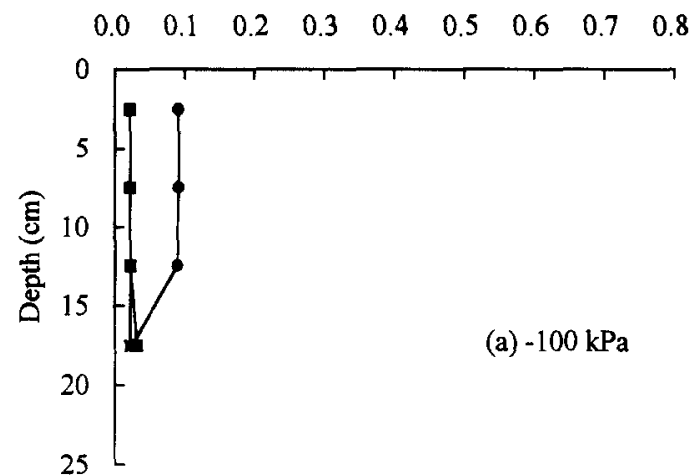

Concentration $\left(\mu \mathrm{g} \mathrm{cm} \mathrm{cm}^{-3} \mathrm{dry}\right.$ soil)
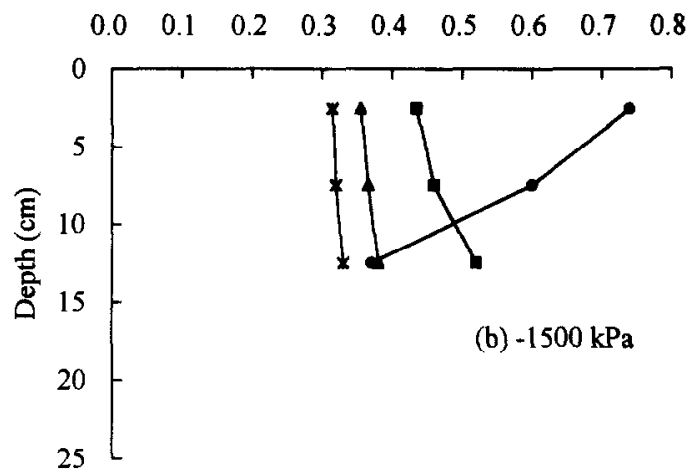

Fig. 3. Predicted changes in substrate concentration with depth following germination of seed inoculated with bacteria and incubation for $7(\mathcal{O}), 14(\mathbf{0}), 21(\mathbf{A})$ and $28 \mathrm{~d}(\mathrm{x})$ in soil at matric potentials of $(\mathrm{a})-100$ $\mathrm{kPa}$ and $(\mathrm{b})-1500 \mathrm{kPa}$. The mathematical model was simulated using the parameters and constants given in Table 1.

also predicts the transient appearance of cells at $20-25 \mathrm{~cm}$, before cell death in the absence of sufficiently high substrate supply leads to their elimination

\section{Comparison of predicted and experimental results}

Experimental data for viable cell concentrations in soil microcosms at both -100 and $-1500 \mathrm{kPa}$ were compared with predictions of the mathematical model (Figures 5-7). Matric potential had a significant effect on experimentally determined viable cell numbers. Analysis of cumulative viable cell number data indicated a highly significant effect $(P<0.001)$. An ANOVA was also performed on each depth interval for all four sampling times. Matric potential had a significant effect $(P<0.05)$ in all cases except on day 7 , when the differences were significant but at a higher probability $(P<0.1)$, and on day 28 when numbers were not significantly different $(P>0.05)$. At -100 $\mathrm{kPa}$, experimental results were predicted well at 0-5, $10-15$ and $15-20 \mathrm{~cm}$ depth intervals (Figure 5). At $5-10 \mathrm{~cm}$ the fit was good (except at day 21 ) and the predicted transient appearance of cells at $20-25 \mathrm{~cm}$ was observed. Although experimental data generally agreed well with model predictions, particularly when taking into consideration experimental variability, sampling was not sufficiently frequent to enable rigorous testing of predictions regarding the nature and timing of the peak in viable cell concentration at different depths. Discrepancies were greatest at greater depths, where cell concentrations were lower and consequently subject to greater experimental variability, both through proximity to lower detection limits and heterogeneity of soil, with consequent effects on the efficiency of sampling procedures.

At $-1500 \mathrm{kPa}$, the quality of fit was good at $0-5$ and $5-10 \mathrm{~cm}$ depth intervals (Figure 6). At $10-15 \mathrm{~cm}$, the model predicted lower viable cell concentrations than observed experimentally and the transient appearance of cells at $15-20 \mathrm{~cm}$ on day 14 was not predicted. At both matric potentials, predictions tended to be greater than experimental values at shallow depths and underestimated cell numbers at greater depths. This probably results from lack of consideration of
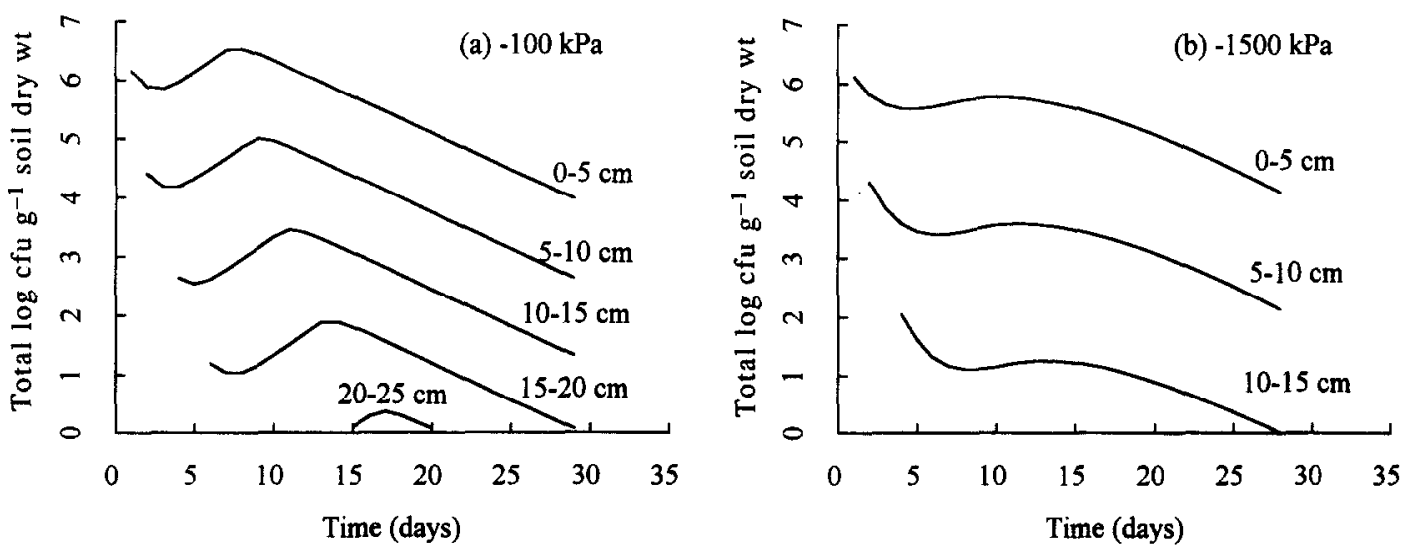

Fig. 4. Predicted changes in the number of bacteria with time at different depths of soil following germination of seed inoculated with bacteria in soil at matric potentials of (a) $-100 \mathrm{kPa}$ and (b) $-1500 \mathrm{kPa}$. The mathematical model was simulated using the parameters and constants given in Table $\mathrm{l}$. 

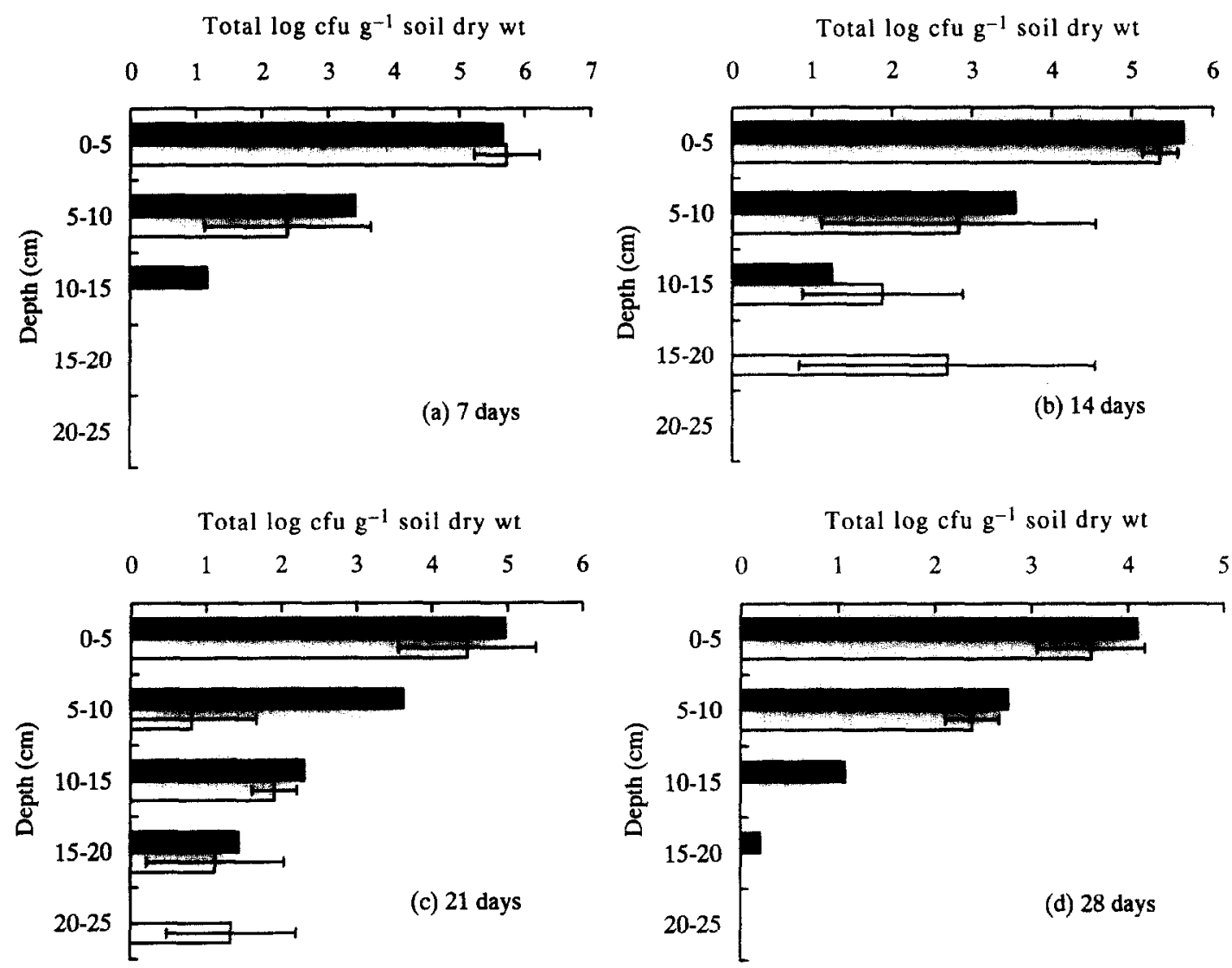

Fig. 5. Comparison of predicted $(\square)$ and experimental $(\square)$ changes in cell numbers with depth following germination of wheat seeds inoculated with $P$. fuorescens 10586(FAC510) and incubation in soil at a matric potential of $-100 \mathrm{kPa}$ for (a) 7, (b) 14 , (c) 21 and (d) $28 \mathrm{~d}$. The mathematical model was simulated using the parameters and constants given in Table 1. Error bars represent SDs of triplicate samples.

movement of cells by mass flow. Although this was minimized by choice of microcosm conditions, some movement of cells may have occurred by mass flow and will have been greater at $-100 \mathrm{kPa}$.

The quality of fit is also represented in Figure 7 by a plot of experimental vs predicted viable cell numbers at all depth and time intervals and both matric potentials. The majority of points fall close to the line of exact fit, which has a gradient of 1 , providing further evidence for the accuracy of the model predictions. There is some deviation at low cell concentrations, which may reflect greater experimental variability.

Sensitivity analysis. Sensitivity analysis was performed to determine which model parameters had greatest influence on predicted behaviour. This was achieved by varying each parameter value by $10 \%$ while all other values were kept constant. The resultant, proportional changes in viable cell numbers at a depth of 5-10 cm after incubation for 10 days are given for each matric potential in Table 2. Any effects of changes in parameter values will accumulate with both depth and time and all proportional changes are consequently greater than the applied change of 0.1 .

As expected, variation in specific growth and death rates of the biomass in water filled pores had no observable effects on viable cell concentration at $-1500 \mathrm{kPa}$, while the kinetic parameters for biomass in non-water-filled pores had no effect at $-100 \mathrm{kPa}$. Cell concentrations were equally sensitive to changes in specific growth rate at each matric potential, but variation in death rate had a slightly greater effect at $-1500 \mathrm{kPa}$. Variation in yield coefficient had no effect, but cell concentrations were sensitive to $K_{\mathrm{s}}$ values. At $-100 \mathrm{kPa}$, sensitivity to $K_{\mathrm{s}}$ was similar to that to $\mu_{\mathrm{mw}}$, but the effect was less at $-1500 \mathrm{kPa}$. In terms of bacterial growth parameters, therefore, at $-100 \mathrm{kPa}$ $\mu_{\mathrm{mw}}, k_{\mathrm{w}}$ and $K_{\mathrm{s}}$ values had similar influence on viable cell concentrations. At $-1500 \mathrm{kPa}$, however, sensitivity was greatest to death rate and least to the $K_{\text {s }}$ value. Root-associated parameter values had less effect on viable cell concentrations. Predictions were relatively insensitive to variation in the fraction of cells translocated to lower depths and the final exudation rate, with a significant effect at $-100 \mathrm{kPa}$ only. Predictions were most sensitive to variation in the initial exudation rate, particularly at $-100 \mathrm{kPa}$.

The model adopts a finite-element approach in place of sets of partial differential equations. This necessarily results in approximation errors, the extent of which can be estimated by changes in the depth and 
time intervals used for simulations. Variation of the depth layer led to changes which were significantly less than those in growth parameters and changes in the simulation time interval led to negligible or undetectable changes in viable cell number. Errors arising from this approximation method are therefore no greater than those arising through variation in the model parameters and are not considered to affect predictions significantly.

\section{DISCUSSION}

The mathematical model quantifies proposed mechanisms for the movement of cells through soil as a result of root growth. For similar amounts of root growth and substrate exudation, it demonstrates the influence of matric potential on subsequent diffusion and utilization of substrate and on the growth and death kinetics of bacterial populations. Simulations of the model increased understanding of the relationships between substrate supply and diffusion and their influence on the bacterial populations. In particular, they demonstrated the need to consider not only the amount of substrate produced but also the rate at which it can diffuse from the root and become available for bacterial growth. Equal amounts of substrate were produced at both matric potentials investigated but growth of cells was initially severely limited at the low matric potential by reduced diffusion away from the root and by reduced diffusion into the soil pore network. The difference between the specific growth rate and specific death rate of the total population was consequently greater at the high matric potential and total biomass production was reduced and substrate accumulated. During the later stages of root colonization, however, accumulated substrate diffused sufficiently to enable increased growth at the lower matric potential and final (day 28) populations at the shallow depths varied little with matric potential. The model assumed the GMM to be the only organism present and competition for substrate with the indigenous population was not considered. In the experimental system competition with the indigenous populations was minimized by sterilisation of seed prior to inoculation with $P$. fluorescens. Sterilization of soil could not be considered as this greatly changes patterns of rhizosphere C flow (Barber and Lynch, 1977) which would influence colonization by $P$. fuorescens. A further simplifying assumption of the model was
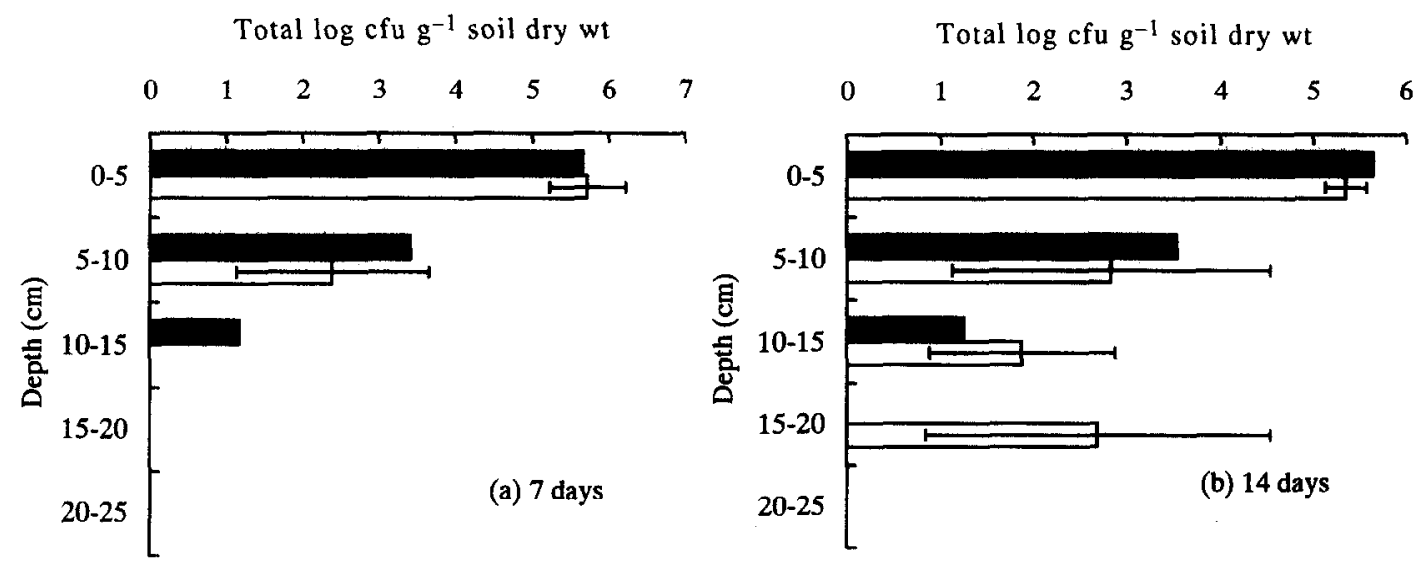

Total $\log \mathrm{cfu}^{-1}$ soil dry wt
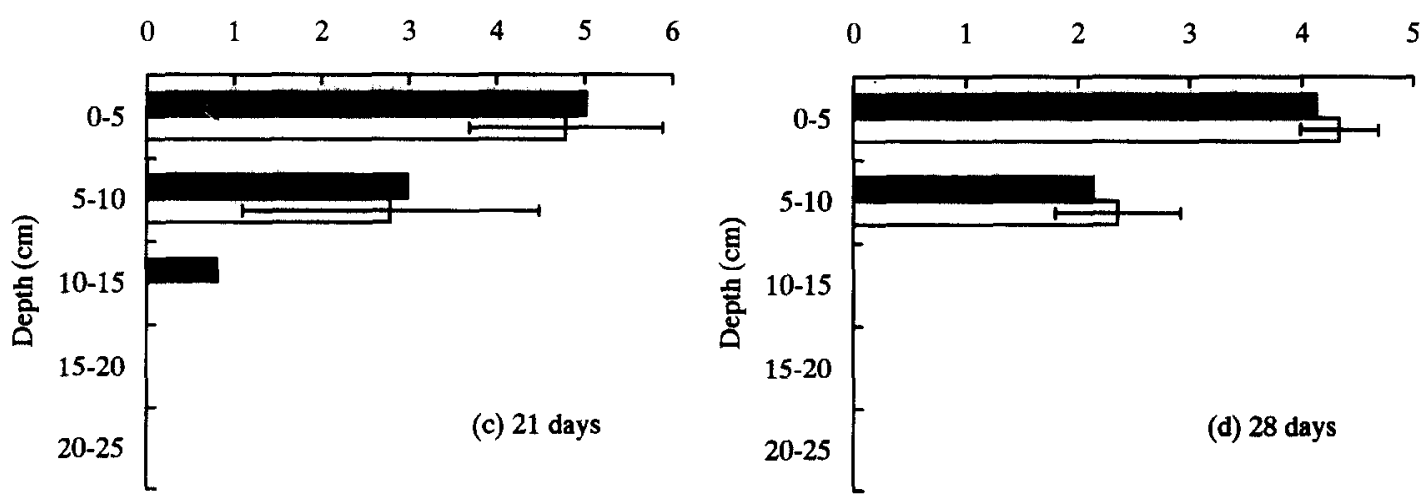

Fig. 6. Comparison of predicted $(\square)$ and experimental $(\square)$ changes in cell numbers with depth following germination of wheat seeds inoculated with $P$. fluorescens 10586 (FAC510) and incubation in soil at a matric potential of $-1500 \mathrm{kPa}$ for (a) 7 , (b) 14 , (c) 21 and (d) $28 \mathrm{~d}$. The mathematical model was simulated using

the parameters and constants given in Table 1. Error bars represent SDs of triplicate samples. 


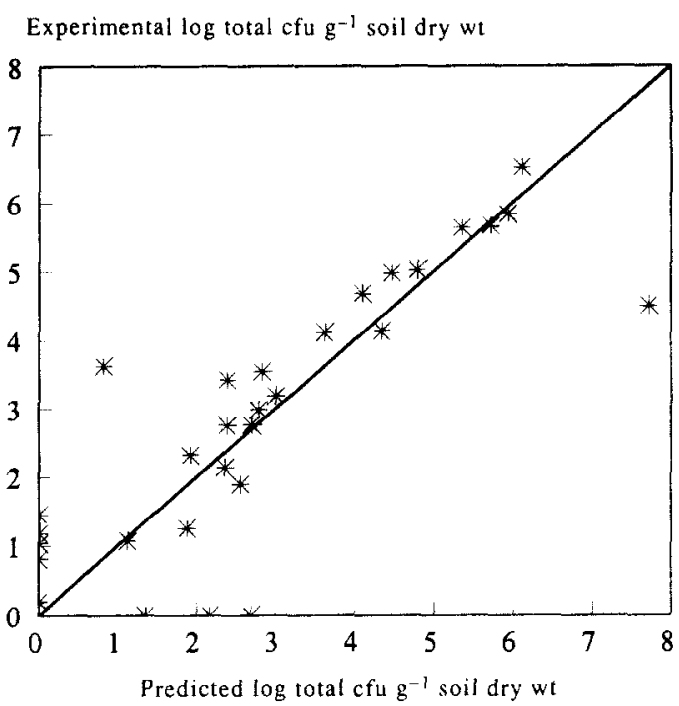

Fig. 7. Comparison of predicted and experimental cell numbers for all depth and time intervals following germination of wheat seeds inoculated with $P$. fluorescens 10586(FAC510) and incubation in soil at matric potentials of -100 and $-1500 \mathrm{kPa}$. The mathematical model was simulated using the parameters and constants given in Table 1. The straight line indicates the line of exact fit between experimental and predicted values.

consideration of bacterial colonization of, and dispersal by, a single root. It is therefore intended as a first step towards modelling the distribution around a root system where factors such as root branching, root density, root longevity and root turnover would be taken into account.

Sensitivity analysis of the model parameters emphasized the importance of the bacterial growth parameters in relation to those associated with substrate production by the root. Changes in viable cell concentrations following variation in maximum specific growth rate, specific death rate and $K_{\mathrm{s}}$ values were greater than those following similar proportional variation in parameters associated with substrate production by the root system. In addition to increasing our understanding of the mechanisms controlling microbial dispersal, and the relative contributions of root and microbial growth, this highlights the importance of accurately describing microbial growth and survival kinetics in soil, and the need for reliable estimates of growth and death parameters. Sensitivity analysis involved variation of single parameters and did not highlight possible interactions amongst parameters.

Although values for some parameters used in simulating the mathematical model were measured experimentally, others required estimation on the basis of previously published values. This is frequently necessary in modelling studies of this sort, even with relatively simple structure, and reduces confidence in the general applicability of the predicted values. However, the aim here was not to produce a general

Table 2. Effects of variation in values of model parameters on predicted viable cell numbers at $5-10 \mathrm{~cm}$ on day 10 ; all parameters were varied by $10 \%$

\begin{tabular}{|c|c|c|c|c|}
\hline Parameter & $\begin{array}{l}\text { Initial } \\
\text { value }\end{array}$ & $\begin{array}{l}\text { Modified } \\
\text { value }\end{array}$ & $\begin{array}{l}\text { Proportion } \\
\text { in viable ce } \\
-100 \mathrm{kPa}\end{array}$ & $\begin{array}{l}\text { difference } \\
\text { number } \\
-1500 \mathrm{kPa}\end{array}$ \\
\hline \multirow[t]{2}{*}{$\mu_{\mathrm{mw}}$} & 0.5 & 0.55 & 2.3 & 20 \\
\hline & 0.5 & 0.45 & 0.43 & 0 \\
\hline \multirow[t]{2}{*}{$\mu_{m d}$} & 0.1 & 0.11 & 0 & 2.28 \\
\hline & 0.1 & 0.09 & 0 & 0.44 \\
\hline \multirow[t]{2}{*}{$k_{\mathrm{w}}$} & 0.02 & 0.022 & 0.39 & 0 \\
\hline & 0.02 & 0.018 & 2.61 & 0 \\
\hline \multirow[t]{2}{*}{$k_{\mathrm{d}}$} & 0.05 & 0.055 & 0 & 0.3 \\
\hline & 0.05 & 0.045 & 0 & 3.3 \\
\hline \multirow[t]{2}{*}{$Y$} & 0.2 & 0.22 & 0 & 0 \\
\hline & 0.2 & 0.18 & 0 & 0 \\
\hline \multirow[t]{2}{*}{$K$} & 4 & 4.4 & 0.48 & 0.66 \\
\hline & 4 & 3.6 & 2.41 & 1.60 \\
\hline \multirow{2}{*}{ Translocated fraction } & 0.04 & 0.044 & 1.1 & 1.1 \\
\hline & 0.04 & 0.036 & 0.9 & 0.9 \\
\hline \multirow[t]{2}{*}{ Initial exudation rate } & 0.01 & 0.011 & 1.80 & 1.50 \\
\hline & 0.01 & 0.009 & 0.55 & 0.63 \\
\hline \multirow[t]{2}{*}{ Final exudation rate } & 0.002 & 0.0022 & 1.23 & 1.003 \\
\hline & 0.002 & 0.0018 & 0.81 & 0.997 \\
\hline
\end{tabular}


predictive model for microbial dispersal but to construct a mechanistic mathematical model, incorporating and quantifying hypotheses regarding root and microbial growth and capable of experimental testing of these underlying hypotheses. This, in turn, required the use of experimental systems which obeyed the simplifying assumptions of the model. So, for example, environmental conditions such as temperature, assumed constant by the model, were maintained constant experimentally. The matric potentials used will have allowed diffusion of substrate, but would have limited bacterial movement and predation. The major mechanism for bacterial movement will therefore have been through transport on the root surface. In addition, the experimental and sampling conditions were designed to optimize uniformity between and within microcosms, to reduce experimental variability.

The quality of agreement between experimental and predicted results provide confidence in the assumptions and mechanisms on which the mathematical model is based. For both matric potentials, there was excellent qualitative agreement for all depths and sampling times. Quantitative fit was also good for much of the data although some discrepancies occurred. These may have been due to experimental variability and certainly, the degree of experimental variability prevented detailed quantitative testing of all aspects of the model predictions, which would require more sensitive and precise experimental systems and techniques. Alternatively, discrepancies may have been due to deficiencies in the model. In particular, lack of consideration of movement of cells by mass flow may have led to discrepancies, particularly at the high matric potential. This, and other simplifying aspects of the model, could be incorporated but the increased complexity would increase the number of parameters for which values would be required and might not increase ability to test the model critically. In addition, simulation of the model involved segmentation of the soil into a number of discrete layers, within which microorganisms and substrate were assumed to be uniformly distributed. This approach is an alternative to use of partial differential equations, which are frequently difficult or impossible to solve analytically. Solution of partial differential equations incorporating the assumptions which form the basis of the model constructed here would not have been possible and simulation therefore required the simplifying assumptions implicit in the finite element approach. The approximation errors which are introduced by this are balanced by increased flexibility in simulating the model. Errors were quantified by sensitivity analysis of both depth and time intervals used in the simulation. Sensitivity to $20 \%$ changes in the size of the depth interval had a similar effect on predicted cell numbers to $10 \%$ changes in some of the growth constants. Changes in time step sizes of $50 \%$ had a negligible effect on predictions.
The model necessarily involves a number of simplifying assumptions and limitations, some of which have been discussed above. A single microorganism and single root are considered, certain parameters of the model could not be measured experimentally and cell movement occurred only by root colonization. The structure of the model also introduces limitations. Discretization introduces approximation errors, the rhizosphere and bulk soil were treated as separate compartments, with instant mixing within each, and gradations in substrate and bacterial concentrations were not considered. A further limitation is the difference in size between vertical and horizontal layers, which to an extent relates to the experimental system used to test the model.

Existing, published theoretical models of the rhizosphere are based on exudation and dispersal of growth-limiting nutrients, with subsequent microbial activity being generally described by traditional equations (Newman and Watson, 1977; Darrah, $1991 \mathrm{a}, \mathrm{b})$. Such models have been used most effectively to investigate microbial population dynamics in an ideal rhizosphere as influenced by a number of exudation scenarios and alternative microbial growth parameters only. In reality, dynamics will depend on soil type and moisture regime. Description of the spread of exudate in the model presented here is comparable to that of earlier models but predicts significantly lower amounts of soluble carbon in the rhizosphere than the model of Darrah (1991a,b). This may be related to use different strategies of rhizodeposition and lower rates of exudation. Previous models have not explicitly considered the rhizosphere as being a soil environment and have therefore neglected the influence of soil architecture on water distribution and therefore microbial activity. As a first attempt at considering such factors, our model has been effective and remains one of the few which has been experimentally tested. Darrah (1991b) points out the importance of predation in rhizosphere models. Predation is known to be influenced by soil type in relation to the distribution of pores of sufficiently large diameter to allow protozoan entry and movement (Postma et al., 1990), further demonstrating the importance of incorporating aspects of soil architecture into rhizosphere descriptions.

Acknowledgements - This study was carried out under a contract from the Department of the Environment (U.K.).

\section{REFERENCES}

Addiscott T. M. and Wagenet R. J. (1985) Concepts of solute leaching in soils: a review of modelling approaches. Journal of Soil Science 36, 411-424.

Amin-Hanjani S. A., Meikle A., Glover L. A., Prosser J. I. and Killham K. (1993) Plasmid and chromosomally encoded luminescence marker systems for detection of Pseudomonas fluorescens in soil. Molecular Ecology 2, 47-54. 
Barber D. A. and Lynch J. M. (1977) Microbial growth in the rhizosphere. Soil Biology \& Biochemistry 9, 305-308.

Bennett R. A. and Lynch J. M. (1981a) Colonization potential in the rhizosphere. Current Microbiology 6, 137-138.

Bennett R. A. and Lynch J. M. (1981b) Bactcrial growth and development in the rhizosphere of gnotobiotic cereal plants. Journal of General Microbiology 125, 95-102.

Darrah P. R. (1991a) Models of the rhizosphere. 1. Microbial population dynamics around a root releasing soluble and insoluble carbon. Plant and Soil 133, 187-199.

Darrah P. R. (1991b) Models of the rhizosphere. 2. Quasi three dimensional simulation of the microbial population dynamics around a root releasing soluble exudates. Plant and Soil 138, 147-158.

Faiz S. M. A. and Weatherley P. E. (1982) Root contraction in respiring plants. New Phytology 92, 333-343.

Filip Z. and Kanazawa S. (1985) Vorkommen von mikroorganismen und enzymaktivaten in organischen und mineralischen Bodenpartikeln. Landwirtschaftliche Forschung 38, 69-71.

Howie W. J., Cook R. J. and Weller D. M. (1987) Effects of matric potential and cell motility on wheat root colonization by fluorescent pseudomonads suppressive to take-all. Phytopathology 77, 286-291.

Kloepper J. W., Hume D. J., Scher F. M., Singleton C., Tipping B., Laliberte M., Frauley K., Kutchaw T., Simonson C., Lifshitz R., Laleska I. and Lee L. (1988) Plant growth-promoting rhizobacteria on canola (rapeseed). Plant Diseases 72, 42-46.

Leben C. (1983) Association of Pseudomonas fuorescens pv. lachrymans and other bacterial pathogens with roots. Phytopathology 73, 577-581.

Liddell C. M. and Parke J. L. (1989) Enhanced colonization of pea taproots by a fluorescent pseudomonad biocontrol agent by water filtration into soil. Phytopathology 79, $1327-1332$

Marshall T. J. (1959) Relations Between Water and Soil Commonwealth Agricultural Bureaux, Farnham Royal.

McDougall B. M. and Rovira A. D. (1970) Sites of exudation of ${ }^{14} \mathrm{C}$-labelled compounds from wheat roots. $\mathrm{New}$ Phytologist 69, 999-1003.
Monod J. (1942) Recherches sur la Croissance des Cultures Bacteriennes, 2nd edn. Hermann, Paris.

Newman E. I. (1985) The rhizosphere: carbon sources and microbial populations. In Ecological Interactions in Soil: Plants, Microbes and Animals (A. H. Fitter, R. Atkinson. D. J. Read and M. B. Usher Eds), pp. 107-121. Blackwell Scientific, Oxford.

Newman E. I. and Watson A. G. (1977) Microbial abundance in the rhizosphere: a computer model. Plant and Soil 48, $17-56$.

Paau A. S. (1989) Improvement of rhizobium inoculants Applied \& Environmental Microbiology 55, 862-865.

Parke J. L., Moen R., Rovira A. D. and Bowen G. D. (1986) Soil water flow affects the rhizosphere distribution of a seed borne biological control agent, Pseudomonas fuorescens. Soil Biology \& Biochemistry 18, 583-588.

Postma J., van Veen J. A. and Walter S. (1989) Influence of different initial soil moisture contents on the distribution and population dynamics of introduced Rhizobium leguminosarum biovar. trifolii. Soil Biology \& Biochemistry 21, 437-442.

Postma J., Hoj-A-Hin C. H. and van Veen J. A. (1990) Role of microniches in protecting introduced Rhizobium leguminosarum biovar. trifolii against competition and predation in soil. Applied \& Environmental Microbiologv 56, 495-502.

Prikryl Z and Vancura V. (1980) Root exudates of plants. VI Wheat root exudation as dependent on growth. concentration gradient of exudates and the presence of bacteria. Plant and Soil 57, 69-83.

Rattray E. A. S., Prosser J. I., Killham K. and Glover L. A. (1990) A luminescence-based non-extractive technique for in situ detection of Escherichia coli in soil. Applied Environmental Microbiology 56, 3368-3374.

Rovira A. D. and Davey C. B. (1974) Biology of the rhizosphere. In The Plant Root and its Emvironment (E. W. Curfova. Ed), pp. 153-204. University of Virginia, Charlottesville, VA.

Schippers B. (1988) Biological control of pathogens with rhizobacteria. Philosophical Transactions of the Roval Society London, Series B 318, 283-292.

Suslow T. V. and Schroth M. N. (1982) Rhizobacteria of sugar beets: effects of seed application and root colonization on yield. Phytopathology 72, 199-206. 